\title{
Inhibition Performance of Some Sulfonylurea on Copper Corrosion in Nitric Acid Solution Evaluated Theoretically by DFT Calculations
}

\author{
Mougo André Tigori ${ }^{*}$, Amadou Kouyaté1, Victorien Kouakou², Paulin Marius Niamien², \\ Albert Trokourey ${ }^{2}$
}

${ }^{1}$ UFR Environnement, Université Jean Lorougnon Guédé, Daloa, Côte d'Ivoire

${ }^{2}$ Laboratoire de Chimie Physique, Université Félix Houphouët Boigny, Abidjan, Côte d'Ivoire

Email:*tigori20@yahoo.fr

How to cite this paper: Tigori, M.A., Kouyaté, A., Kouakou, V., Niamien, P.M. and Trokourey, A. (2020) Inhibition Performance of Some Sulfonylurea on Copper Corrosion in Nitric Acid Solution Evaluated Theoretically by DFT Calculations. Open Journal of Physical Chemistry, 10, 139-157.

https://doi.org/10.4236/ojpc.2020.103008

Received: April 5, 2020

Accepted: July 31, 2020

Published: August 3, 2020

Copyright $\odot 2020$ by author(s) and Scientific Research Publishing Inc. This work is licensed under the Creative Commons Attribution International License (CC BY 4.0).

http://creativecommons.org/licenses/by/4.0/

\begin{abstract}
The theoretical study of chlorpropamide, tolazamide and glipizide was carried out by the Density Functional Theory (DFT) at B3LYP/6-31G(d) level. This study made it possible to determine the global reactivity parameters in order to better understand the interactions between the molecules studied and the copper surface. Then, the determination of local reactivity indices (Fukui functions and dual descriptor) on these molecules resulted in the precision on the most probable centers of nucleophilic and electrophilic attacks within each molecule. The results obtained, show that chloropropamide, tolazamide and glipizide can be good inhibitors against copper corrosion. Thus, the mechanism of copper corrosion inhibition of these compounds in nitric acid solution has been explained by means of theoretical calculations.
\end{abstract}

\section{Keywords}

Chlorpropamide, Tolazamide, Glipizide, Density Functional Theory, Copper Corrosion

\section{Introduction}

Corrosion is a chemical degradation of a material and the alteration of its properties by chemical reaction with the surrounding environment. It is a phenomenon that affects many structures by rendering them unusable for their intended 
application, particularly those made of metallic materials. Indeed, metallic materials, especially copper, are widely used in industry because of its remarkable physical, mechanical, anti-corrosion and biological properties [1]. During its use, copper is exposed to the action of aggressive media [2] [3], such as acid solutions which act as corrosive agents. These acid solutions, which very often contribute to copper degradation, are used in several areas [4] [5], namely: pickling or acid cleaning, oil well stimulation, removal of localized deposits and industrial synthesis processes. For reducing this phenomenon, corrosion inhibitors, especially organic molecules, are used. These first act by adsorption on the surface of metals before intervening in the corrosion reaction process to reduce the speed [6] [7]. Several works [8]-[13] have shown that organic compounds, corrosion inhibitors contain heteroatoms $(\mathrm{S}, \mathrm{P}, \mathrm{O}, \mathrm{N})$ and/or $\pi$ bonds including all the aromatic rings in their molecular structure which can offer special active electrons or vacant orbitals capable of accepting or giving electrons. In order to preserve the environment, the solution of non-toxic organic inhibitors seems to be the most widely used method [14] [15] [16] in both industry and crafts. So, to inhibit the corrosion of metals, several researches have been directed towards natural products [17] [18] extracted from plant sources and pharmaceutical molecules [19] [20]. Since the adsorption of an organic compound is linked to its molecular structure, the use of quantum chemical methods is more than necessary to achieve the descriptive parameters of the molecules. Many studies in the literature [21] [22] [23] show the correlations between the organic molecules chemical reactivity and their descriptor parameters. Theoretical calculations [24] are today an indispensable tool for the control of molecular structures, the physico-chemical properties of matter and the understanding of metal-molecule interactions. This activity is favoured by the powerful computers and the quality of software (Gaussian, Gamess, Molpro, NWchem, etc.) which have enabled the development of numerical simulation and molecular modelling methods. These calculations [25]-[31] contribute to a better understanding of inhibition properties and reactive behavior of the molecules studied. So, they give access to the molecules parameters such as highest occupied molecular orbital energy $\left(E_{\mathrm{HO} о}\right)$, lowest unoccupied molecular orbital energy $\left(E_{\mathrm{LUMO}}\right)$, energy gap $(\Delta E)$, dipole moment $(\mu)$, electronegativity $\chi$, hardness $\eta$, softness $S$, electrophylicity index $\omega$. Local parameters (Fukui function $f_{k}^{+}$or $f_{k}^{-}$and dual descriptor $\left(\Delta f_{k}^{+}\right.$or $\Delta f_{k}^{-}$) allowed to access the nucleophilic and electrophilic attack sites of the molecules in order to better understand the mechanism of corrosion inhibition by organic molecules.

The objective of this work is to study theoretically the inhibition properties of three antidiabetic drugs of the sufonylureas family which are chlorpropamide, tolazamide, and glipizide. The choice of these molecules is based on the existence of heteroatoms such as nitrogen, oxygen and sulfur; $\pi$ bonds and aromatic rings which are important factors to be good inhibitors and they are not toxic at low concentration. 


\section{Materials and Methods}

\subsection{Studied Molecules}

The molecular structure of each compound is given by Figure 1.

\subsection{DFT Calculations}

In this work, the quantum chemical calculations were performed with Gaussian 09 W software [32]. Density Functional Theory (DFT) is an application incorporated in the commercial software (Gaussian). This application has permitted to optimize the geometry of each molecule at B3LYP level, with 6-31G(d) basis set. Indeed B3LYP with Becke's three parameter Lee-Yang Parr hybrid functional, provides good results which allow to describe with precision the behavior of organic compounds [33] [34]. These calculations provided to access to the global and local descriptor parameters, which will facilitate the understanding of metal-molecule interactions. The optimized structure of the studied compounds is given in Figure 2.

The determination of global reactivity parameters helps to explain the inhibition properties of organic molecules.

The electronegativity is related to the chemical potential by the following equation [35].

$$
\chi=-\mu_{p}=\left(\frac{\partial E}{\partial N}\right)_{v(r)}
$$

It is a global property of the molecular system. The chemical potential is equal to the slope of the total energy as a function of the number of electrons $N$ at constant external potential $v(r)$.

According to Koopman's theorem [36] the negative value of $E_{\mathrm{HOMO}}$ is defined by the ionization potential $(I)$ and is given by:

$$
I=-E_{\text {Номо }}
$$<smiles>CCCNC(=O)NS(=O)(=O)c1ccc(Cl)cc1</smiles>

4-chloro-N-(propylcarbarmoyl)benzene sulfonamide or chlorpropamide<smiles>Cc1ccc(S(=O)(=O)NC(=O)NN2CCCCCC2)cc1</smiles>

$\mathrm{N}$-[(azepan-1-ylamino)carbonyl)]-4-methyl benzene sulfonamide or tolazamide<smiles>Cc1cnc(C(=O)NCCc2ccc(S(=O)(=O)NC(=O)NC3CCCCC3)cc2)cn1</smiles>

5-methyl-N-(2-\{4-[(cyclohexylcarbamoyl)sulfamoyl]phenyl\}ethyl) pyrazine-2-carboxamide ou glipizide

Figure 1. Chemical structure of the inhibitors investigated. 


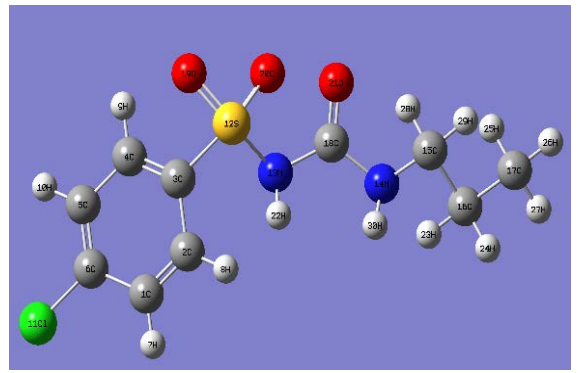

Chlorpropamide (CPA)

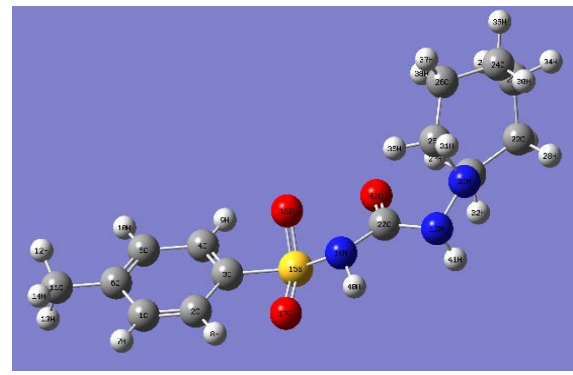

Tolazamide(TZA)

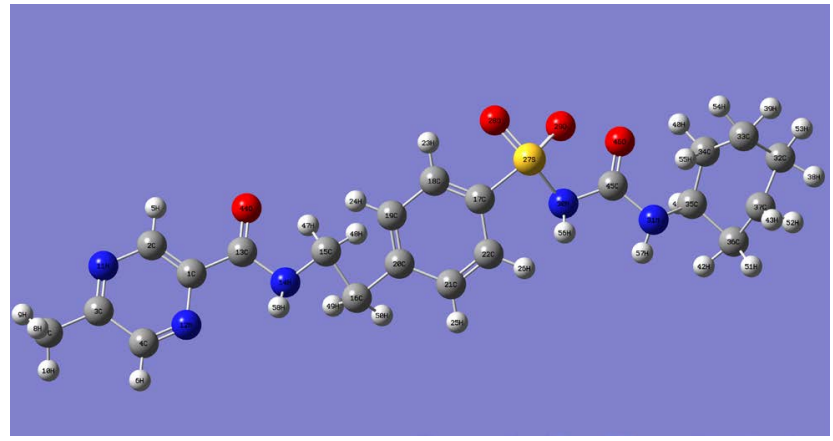

Glipizide (GP)

Figure 2. Optimized structure of CPA, TZA and GP with B3LYP/6-31G(d) method.

The lowest unoccupied molecular orbital energy $E_{\mathrm{LUMO}}$ is another global parameter whose negative value is defined by the electronic affinity $(A)$ according to the following expression:

$$
A=-E_{\text {LUMO }}
$$

Using finite difference approximation, $\mu_{P}$ chemical potential can be expressed as a function of the ionization potential $I$ and the electron affinity $A$ :

$$
\mu_{p}=-\frac{I+A}{2}
$$

Hardness $\eta$ and the softness $S$ [37] [38] are obtained from the first derivative of chemical potential or the second derivative of the total energy:

$$
\eta=\left(\frac{\partial \mu_{P}}{\partial N}\right)_{v(r)}=\left(\frac{\partial^{2} E}{\partial N^{2}}\right)_{v(r)}=\frac{1}{S}
$$

These fundamental quantities in acids and bases theory developed by Pearson [39] have been used to interpret chemical reactions results. They can also be written as a function of ionization potential $(I)$ and electron affinity $(A)$. Softness reflects the capacity of an atom or molecule to retain an acquired charge [40] [41]. The hardness of an atom or molecule is the energy required for its dismutation; it is the resistance to charge transfer.

$$
\begin{aligned}
& \eta=\frac{I-A}{2}=\frac{E_{\mathrm{LUMO}}-E_{\mathrm{HOMO}}}{2} \\
& S=\frac{2}{I-A}=\frac{2}{E_{\mathrm{LUMO}}-E_{\mathrm{HOMO}}}
\end{aligned}
$$


The electrophilicity index [42] is used to characterize the ability of a molecule to donate or accept electrons. It can then be expressed by:

$$
\omega=\frac{\mu_{P}^{2}}{2 \eta}=\frac{(I+A)^{2}}{4(I-A)}
$$

The fraction of electrons transferred $(\Delta N)$ from the inhibitor molecule to the metal was calculated according to Pearson's electronegativity relationship [43]:

$$
\Delta N=\frac{\chi_{C u} \chi_{i n h}}{2\left(\eta_{C u}+\eta_{i n h}\right)}
$$

where $\chi_{C u}$ and $\eta_{C u}, \chi_{i n h}$ and $\eta_{i n h}$ denote the electronegativity and hardness of copper and the inhibitor molecule respectively. In this study, we use the theoretical value of $\chi_{C u}=4.98 \mathrm{eV}[44]$ and $\eta_{C u}=0$, assuming that for a metallic charge $I=A$ [45] because they are softer than the neutral metallic atoms.

The corrosion inhibition of a metal is influenced by the local reactivity based on Fukui functions. Their values are used to identify the atoms in the inhibitor that can undergo either electrophilic or nucleophilic attack.

Using finite difference approximation, the Fukui functions $f^{+}(r)$ and $f^{-}(r)$ are respectively equal to the electron densities of LUMO and HOMO orbitals [46] and are defined as follows:

$$
\begin{gathered}
\text { Nucleophilic attack: } f^{+}(r)=\rho_{N+1}(r)-\rho_{N}(r) \approx \rho_{\text {LUMO }}(r) \\
\text { Electrophilic attack: } f^{-}(r)=\rho_{N}(r)-\rho_{N-1}(r) \approx \rho_{\text {HОМО }}(r)
\end{gathered}
$$

where $\rho_{N}(r)$ is the electron density at a point $r$ in space around the molecule, $N$ corresponds to the number of electrons in the neutral molecule, $N+1$ corresponds to an anion with an electron added to LUMO of the neutral molecule and $N-1$ corresponds to a cation with an electron removed from HOMO of the neutral molecule.

These functions are condensed on atom $k$ where the electron density is replaced by an electronic population $q_{k}$. In this case the previous expressions become [47]:

$$
\begin{array}{ll}
\text { Nucleophilic Attack: } & f_{k}^{+}=q_{k}(N+1)-q_{k}(N) \\
\text { Electrophilic attack: } & f_{k}^{-}=q_{k}(N)-q_{k}(N-1)
\end{array}
$$

where $q_{k}(N+1), q_{k}(N)$ and $q_{k}(N-1)$ are the electronic population of atom $k$ in $(N+1), N$ and $(N-1)$ of electrons systems.

A dual descriptor [31] has been introduced recently to determine the individual sites within the molecule with particular behavior. It is given by the following equation:

$$
\Delta f_{k}(r)=\left(\frac{\partial f_{k}(r)}{\partial N}\right)_{v(r)}
$$

The condensed form of the dual descriptor is given by the following relation:

$$
\Delta f_{k}(r)=f_{k}^{+}-f_{k}^{-}
$$


when $\Delta f_{k}(r)>0$, the process is driven by a nucleophilic attack, and the atom $k$ acts as an electrophile, for $\Delta f_{k}(r)<0$ the process is driven by an electrophilic attack and the atom $\mathrm{k}$ acts as a nucleophile.

\section{Results and Discussion}

\subsection{Global Reactivity}

The different formulas listed above have been used to determine the reactivity descriptors. DFT calculations permit to characterize the reactivity properties of chemical compounds in order to predict the correlation between their molecular structure and their possible behavior like corrosion inhibitors. The different values of these quantum chemical parameters of the molecules are recorded in Table 1.

The highest occupied molecular orbital energy $\left(E_{\text {Номо }}\right)$ is a reactivity parameter of molecules associated with the ability to provide electrons. A high value of this parameter indicates a good tendency to donate electron to an appropriate acceptor with low empty energy orbital (metal) [48]. Indeed a metal has a high tendency to accept electrons from an electron donor (organic molecule) into its lowest unoccupied orbital, which could create an electron layer on the metal surface. In our case the high $E_{\mathrm{HOMO}}$ values of the three molecules show their high ability to give electrons to copper and this justifies their good performance in inhibiting copper corrosion in nitric acid solution. The $E_{\text {номо }}$ values of the molecules studied increase in the following order: GP $>$ TZA $>$ CPA, which means that GP could have high inhibition efficiency.

Table 1. Quantum chemical parameters of the studied compounds calculated using B3LYP/6-31G(d).

\begin{tabular}{|c|c|c|c|}
\hline Parameters & CPA & TZA & GP \\
\hline$E_{\text {Hомо }}(\mathrm{eV})$ & -6.4496 & -6.1312 & -5.3947 \\
\hline$E_{\mathrm{LUMO}}(\mathrm{eV})$ & -0.8812 & -1.7611 & -2.1099 \\
\hline Energy gap $\Delta E(\mathrm{eV})$ & 5.5685 & 4.3701 & 3.2848 \\
\hline Dipole moment $\mu$ (D) & 10.2324 & 2.0366 & 8.3715 \\
\hline Ionization energy $I(\mathrm{eV})$ & 6.4496 & 6.1312 & 5.3947 \\
\hline Electron affinity $A(\mathrm{eV})$ & 0.8812 & 1.7611 & 2.1099 \\
\hline Electronegativity $\chi(\mathrm{eV})$ & 3.6654 & 3.9462 & 3.7523 \\
\hline Hardness $\eta(\mathrm{eV})$ & 2.7842 & 2.1851 & 1.6424 \\
\hline Softness $S(\mathrm{eV})^{-1}$ & 0.3592 & 0.4576 & 0.6089 \\
\hline Fraction of electron transferred $\Delta N$ & 0.2360 & 0.2366 & 0.3737 \\
\hline Electrophylicity index $\omega$ & 2.4127 & 3.5634 & 4.2863 \\
\hline Total energy $E_{T}(\mathrm{Ha})$ & -1581.1338 & -1333.8295 & -1787.3716 \\
\hline
\end{tabular}


The ability of a molecule to form bonds with a metal surface [49] also depends on the $E_{\mathrm{LUmo}}$ (lowest unoccupied molecular orbital energy) value. Indeed the binding ability of the inhibitor to the metal surface increases with increasing of HOMO and decreasing of LUMO energy values. In general organic compounds do not only donate electron to the unoccupied $\mathrm{d}$ orbital of the metal ion such as $\mathrm{Cu}^{2+}\left([\mathrm{Ar}] 3 \mathrm{~d}^{9}\right)$, but can also accept electron from the $\mathrm{d}$ orbital of the metal, leading to the formation of a feedback bond. According to the literature excellent corrosion inhibitors are usually those organic compounds which not only offer electrons to unoccupied orbital of the metal, but also accept free electrons from the metal [50]. In this work, the low $E_{\mathrm{LUMO}}$ values of the studied molecule show that they have a tendency to accept electrons from the metal copper. In Table 1, GP has the lowest value of $E_{\mathrm{LUMO}}$, so it could be the best inhibitor. This transfer or sharing of electrons between the molecules and the unsaturated "d" orbitals of the metal surface allows the formation of covalent bonds (important bonds) reflecting the chemical adsorption.

The value of the energy gap $\Delta E=E_{\mathrm{LUMO}}-E_{\mathrm{HOMO}}$ is a parameter that gives information about the reactivity of a chemical species. Indeed a high value of $\Delta E$ means that the molecule is less reactive [51]. When $\Delta E$ value of a molecule is low, this favors the exchanges of electrons between this molecule and the metal because it is easier to remove an electron from HOMO orbital to LUMO. We observe that $\Delta E$ value of the studied compound are low, which justifies their good inhibition performance. Comparing the different values of $\Delta E$ in Table 1 , GP has the lowest value therefore it could be the good inhibitor. This low value of $\triangle E$ for GP is justified by its large molecular structure with more heteroatoms $(\mathrm{O}, \mathrm{N}$ and $\mathrm{S})$ than the other two compounds. The value of $\Delta E$ for CPA is the highest, which could be justified by the presence of chlorine in this molecule. The HOMO-LUMO diagram in Figure 3 shows an approximation of the frontier molecular orbitals energy gap to be franked in order to remove an electron from HOMO toward LUMO for each molecule.

The dipole moment $(\mu)$ measures the polarity of a bond and is related to the distribution of electronic charges in the molecule and also reflects the ability of the molecule to adsorb to the metal surface. According to some authors [52] [53] the higher dipole moment of a molecule, the greater its ability to adsorb on the surface of a metal. However, many other authors [54] [55] state that low dipole moment values favour the adsorption process. In our case CPA and GP have larger dipole moments than TZA. Thus, taking into account the divergent views, there is no significant relationship between dipole moment and inhibition efficiency [56].

Ionization energy $(I)$ and electron affinity $(A)$, which are respectively associated with the HOMO and LUMO energies, are fundamental descriptors of the chemical reactivity of a molecule. A high ionization energy indicates that the molecule is stable and inert to any chemical reaction, while a low ionization energy indicates that the molecule is reactive [57]. The low ionization energy of 


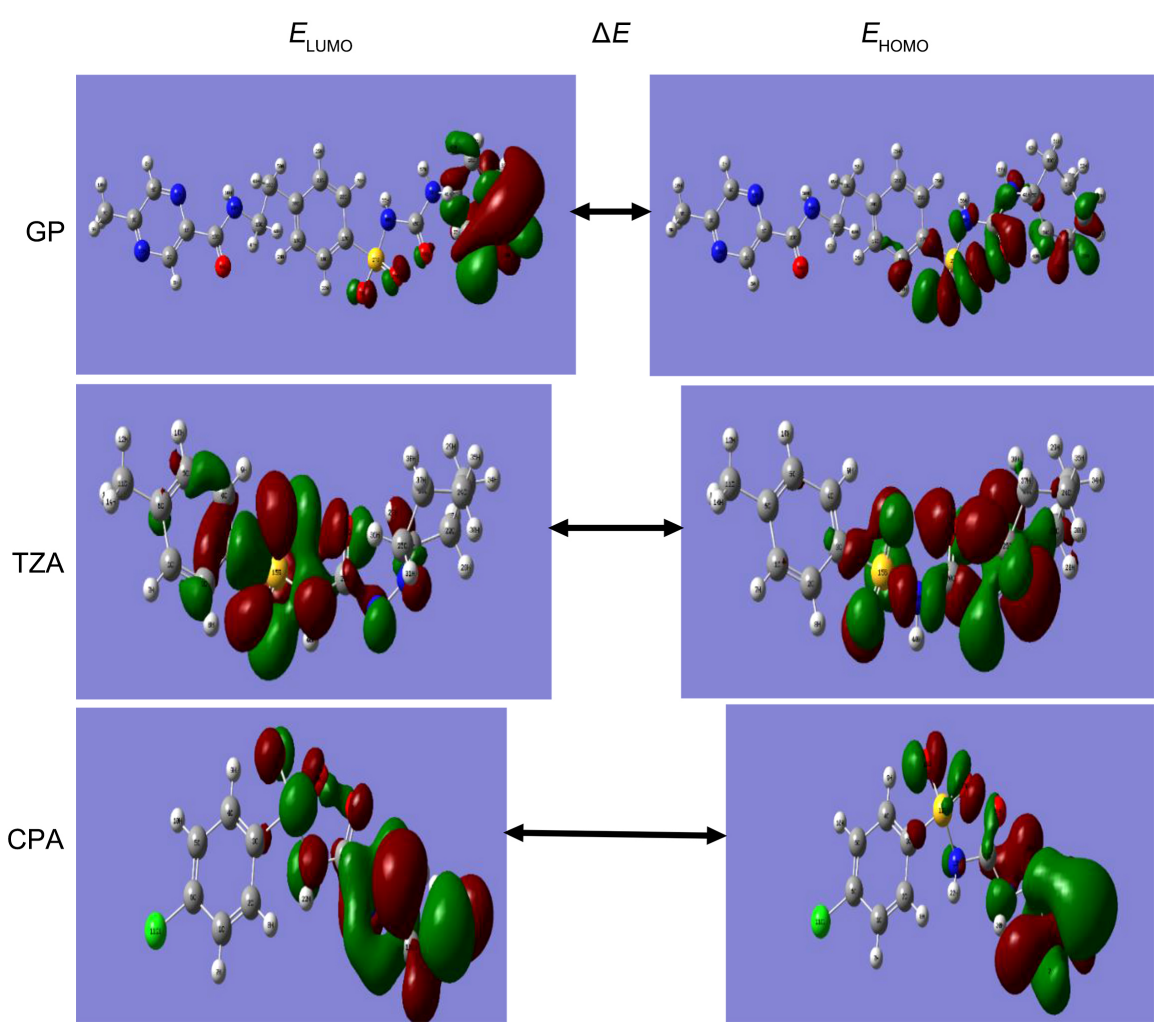

Figure 3, Energy diagram LUMO-HOMO of GP, TZA and CPA.

the three molecules indicates their high inhibition efficiency. The lowest value of GP confirms its greater inhibition efficiency.

The electronegativity $(\chi)$ of a molecule reflects its ability to attract electrons. The electronegativity values of the three molecules are lower than copper (4.98), which means that copper has the best capacity of attraction. This information indicates that there is a possible movement of electrons from each molecule towards copper.

The probable ability of a molecule to interact with a metal surface is translated by the global softness $(S)$ and global hardness $(\eta)$. A good inhibitor has a high softness value and a low hardness value [58]. The different molecules in our case have low hardness values and high softness values. So, these values show that the three (3) molecules studied are good inhibitors and GP which has the lowest hardness value $(1.6424 \mathrm{eV})$ and the highest softness value $\left(0.6089(\mathrm{eV})^{-1}\right)$ would have the best inhibition efficiency.

The Fraction of electron transferred $(\Delta N)$ of a molecule reflects its ability to donate electrons. According to Lukovits's study, if $\Delta N<3.6$ [59] it means that the inhibition efficiency increases with the ability of molecules to donate electrons. In our study, the fractions of electrons transferred from molecules are below 3.6 and are in the order GP > TZA > CPA; this reflects that the good inhibition performance of these molecules is related to the transfer of electrons from these compound to the metal. GP has the best inhibition performance compared to the other two molecules. 
The electrophilicity index $(\omega)$ measures the propensity of chemical species to accept electrons. A high value of $\omega$ [42] describes a good electrophile, while a low value of $\omega$ describes a good nucleophile. In our case the electrophilicity index values of the different molecules are high, which expresses that the molecule have a good capacity to accept electrons from copper.

The total energy is an indicator that provides information on metal-molecule interaction. The total energy of a system is the sum of the internal, potential and kinetic energy. Hohenberg and Kohn [60] have shown that the total energy of a system, including that of the many bodily effects of electrons (exchange and correlation) in the presence of a static external potential (atomic nuclei), is a unique functional of charge density. The exact electron density is the one that minimizes the functional energy. In our work, the total energy of the three molecules is less than zero $\left(E_{T}<0\right)$ and $\eta>0$, the charge transfer from each molecule to the metal is energetically favorable [61]. In this context, there is an interaction between the molecules and the metal surface.

\subsection{Local Reactivity}

Information on the local reactivity of the molecules is provided by the Fukui functions and the dual descriptor. Their values allow us to determine the probable electrophilic and nucleophilic attacks sites.

The atom having the highest value of $f_{k}^{+}$or $\Delta f_{k}(r)>0$, represents the most likely centre for nucleophilic attack (electron receiving centre), this centre is associated with the LUMO orbital. The atom whose value of $f_{k}^{-}$is the highest or $\Delta f_{k}(r)<0$, represents the most probable site of electrophilic attack (electron emission centre), this centre is associated with the HOMO orbital. The dual descriptor is defined in the interval $-1 \leq \Delta f_{k}(r) \leq 1$ [31], which makes it easier to characterize the reactivity of a molecule. The different values are recorded in Tables 2-4.

According to Martínez-Araya's study the dual descriptor is more accurate local reactivity descriptor than Fukui function [62]. Although the Fukui function has the ability to reveal nucleophilic and electrophilic sites in a molecule, the dual descriptor is able to unambiguously specify true sites for nucleophilic and electrophilic attacks; furthermore, the dual descriptor is less affected by the lack of relaxation terms than the Fukui function [62]. In this context we used the Fukui function and the dual descriptor to better explain the reactivity of the molecules.

In Table 2, the atom $S(12)$ has the highest value of $f_{k}^{+}$and the positive value of $\Delta f_{k}(r)$ so, $S(12)$ is the nucleophilic attack centre for CPA. On the other hand, $O(19)$ has the highest value of $f_{k}^{-}$and does not have the negative value of $\Delta f_{k}(r)$. Therefore the atom $O(20)$ which has the negative value of $\Delta f_{k}(r)$ is the electrophilic attack centre for CPA. The reactivity parameters of TZA depicted in Table 3 implies that $S$ (15) has the highest value of $f_{k}^{+}$and $\Delta f_{k}(r)>0$ so, it is the nucleophilic attack centre. The electrophilic attack centre 
Table 2. Mulliken atomic charges, Fukui functions and dual descriptor by B3LYP/6-31G(d) of CPA.

\begin{tabular}{|c|c|c|c|c|c|c|}
\hline atom & $q_{k}(N+1)$ & $q_{k}(N)$ & $q_{k}(N-1)$ & $f_{k}^{+}$ & $f_{k}^{-}$ & $\Delta f_{k}(r)$ \\
\hline $1 \mathrm{C}$ & -0.113896 & -0.128239 & -0.136576 & 0.014343 & 0.008337 & 0.006006 \\
\hline $2 \mathrm{C}$ & -0.153185 & -0.160351 & -0.160952 & 0.007166 & 0.000601 & 0.006565 \\
\hline $3 \mathrm{C}$ & -0.128871 & -0.117975 & -0.092014 & -0.010896 & -0.025961 & 0.015065 \\
\hline $4 \mathrm{C}$ & -0.136268 & -0.158123 & -0.158767 & 0.021855 & 0.000644 & 0.021211 \\
\hline $5 \mathrm{C}$ & -0.130301 & -0.14272 & -0.151753 & 0.012419 & 0.009033 & 0.003386 \\
\hline $6 \mathrm{C}$ & -0.062419 & -0.071023 & -0.075527 & 0.008604 & 0.004504 & 0.0041 \\
\hline $7 \mathrm{H}$ & 0.1872 & 0.145508 & 0.118981 & 0.041692 & 0.026527 & 0.015165 \\
\hline $8 \mathrm{H}$ & 0.138595 & 0.116631 & 0.114588 & 0.021964 & 0.002043 & 0.019921 \\
\hline $9 \mathrm{H}$ & 0.230501 & 0.199241 & 0.184904 & 0.03126 & 0.014337 & 0.016923 \\
\hline $10 \mathrm{H}$ & 0.198351 & 0.155119 & 0.12508 & 0.043232 & 0.030039 & 0.013193 \\
\hline $11 \mathrm{Cl}$ & 0.067729 & -0.026445 & -0.079736 & 0.094174 & 0.053291 & 0.040883 \\
\hline $12 \mathrm{~S}$ & 1.0024 & 0.87433 & 0.822842 & 0.12807 & 0.051488 & 0.076582 \\
\hline $13 \mathrm{~N}$ & -0.696713 & -0.713016 & -0.730488 & 0.016303 & 0.017472 & -0.001169 \\
\hline $14 \mathrm{~N}$ & -0.660934 & -0.685025 & -0.655434 & 0.024091 & -0.029591 & 0.053682 \\
\hline $15 \mathrm{C}$ & -0.095675 & -0.139918 & -0.19329 & 0.044243 & 0.053372 & -0.009129 \\
\hline $16 \mathrm{C}$ & -0.396184 & -0.379851 & -0.405925 & -0.016333 & 0,026074 & -0.042407 \\
\hline $17 \mathrm{C}$ & -0.464976 & -0.454883 & -0.4641 & -0.010093 & 0.009217 & -0.01931 \\
\hline $18 \mathrm{C}$ & 0.766023 & 0.753065 & 0.729029 & 0.012958 & 0.024036 & -0.011078 \\
\hline 190 & -0.372774 & -0.458655 & -0.557838 & 0.085881 & 0.099183 & -0.013302 \\
\hline 200 & -0.27058 & -0.290822 & -0.360331 & 0.020242 & 0.069509 & -0.049267 \\
\hline $21 \mathrm{O}$ & -0.273249 & -0.31759 & -0.321473 & 0.044341 & 0.003883 & 0.040458 \\
\hline $22 \mathrm{H}$ & 0.341417 & 0.3197 & 0.300627 & 0.021717 & 0.019073 & 0.002644 \\
\hline $23 \mathrm{H}$ & 0.257081 & 0.246558 & 0.232444 & 0.010523 & 0.014114 & -0.003591 \\
\hline $24 \mathrm{H}$ & 0.296466 & 0.251505 & 0.167179 & 0.044961 & 0.084326 & -0.039365 \\
\hline $25 \mathrm{H}$ & 0.170276 & 0.138298 & 0.120989 & 0.031978 & 0.017309 & 0.014669 \\
\hline $26 \mathrm{H}$ & 0.344348 & 0.24117 & 0.144301 & 0.103178 & 0.096869 & 0.006309 \\
\hline $27 \mathrm{H}$ & 0.198034 & 0.118959 & 0.059465 & 0.079075 & 0.059494 & 0.019581 \\
\hline $28 \mathrm{H}$ & 0.212141 & 0.173832 & 0.110065 & 0.038309 & 0.063767 & -0.025458 \\
\hline $29 \mathrm{H}$ & 0.186858 & 0.144775 & 0.120451 & 0.042083 & 0.024324 & 0.017759 \\
\hline $30 \mathrm{H}$ & 0.358603 & 0.325946 & 0.29326 & 0.032657 & 0.032686 & 0.069971 \\
\hline
\end{tabular}


Table 3. Mulliken atomic charges, Fukui functions and dual descriptor by B3LYP/6-31G(d) of TZA.

\begin{tabular}{|c|c|c|c|c|c|c|}
\hline atom & $q_{k}(N+1)$ & $q_{k}(N)$ & $q_{k}(N-1)$ & $f_{k}^{+}$ & $f_{k}^{-}$ & $\Delta f_{k}(r)$ \\
\hline $1 \mathrm{C}$ & -0.150079 & -0.168827 & -0.186024 & 0.018748 & 0.017197 & 0.001551 \\
\hline $2 \mathrm{C}$ & -0.102883 & -0.104888 & -0.121603 & 0.002005 & 0.016715 & -0.01471 \\
\hline $3 \mathrm{C}$ & -0.093009 & -0.078401 & -0.043653 & -0.014608 & -0.034748 & 0.02014 \\
\hline $4 \mathrm{C}$ & -0.140646 & -0.152102 & -0.173683 & 0.011456 & 0.021581 & -0.010125 \\
\hline $5 \mathrm{C}$ & -0.16942 & -0.184597 & -0.200968 & 0.015177 & 0.016371 & -0.001194 \\
\hline $6 \mathrm{C}$ & 0.144891 & 0.14186 & 0.138651 & 0.003031 & 0.003209 & -0.000178 \\
\hline $7 \mathrm{H}$ & 0.177388 & 0.137516 & 0.078893 & 0.039872 & 0.058623 & -0.018751 \\
\hline $8 \mathrm{H}$ & 0.20338 & 0.183871 & 0.151664 & 0.019509 & 0.032207 & -0.012698 \\
\hline $9 \mathrm{H}$ & 0.190888 & 0.169664 & 0.129557 & 0.021224 & 0.040107 & -0.018883 \\
\hline $10 \mathrm{H}$ & 0.17332 & 0.135778 & 0.079674 & 0.037542 & 0.056104 & -0.018562 \\
\hline $11 \mathrm{H}$ & -0.520544 & -0.518746 & -0.516763 & -0.001798 & -0.001983 & 0.000185 \\
\hline $12 \mathrm{H}$ & 0.185442 & 0.165257 & 0.13844 & 0.020185 & 0.026817 & -0.006632 \\
\hline $13 \mathrm{H}$ & 0.199869 & 0.174764 & 0.142628 & 0.025105 & 0.032136 & -0.007031 \\
\hline $14 \mathrm{H}$ & 0.183789 & 0.163624 & 0.137009 & 0.020165 & 0.026615 & -0.00645 \\
\hline $15 \mathrm{~S}$ & 1.007398 & 0.874407 & 1.044639 & 0.132991 & -0.170232 & 0.303223 \\
\hline 160 & -0.379784 & -0.411896 & -0.539994 & 0.032112 & 0.128098 & -0.095986 \\
\hline $17 \mathrm{O}$ & -0.431687 & -0.514955 & -0.63517 & 0.083268 & 0.120215 & -0.036947 \\
\hline $18 \mathrm{~N}$ & -0.600684 & -0.627454 & -0.630237 & 0.02677 & 0.002783 & 0.023987 \\
\hline $19 \mathrm{~N}$ & -0.405071 & -0.445595 & -0.47315 & 0.040524 & 0.027555 & 0.012969 \\
\hline $20 \mathrm{C}$ & 0.602502 & 0.597201 & 0.573459 & 0.005301 & 0.023742 & -0.018441 \\
\hline $21 \mathrm{C}$ & -0.199144 & -0.146279 & -0.121506 & -0.052865 & -0.024773 & -0.028092 \\
\hline $22 \mathrm{C}$ & -0.287473 & -0.263408 & -0.255647 & -0.024065 & -0.007761 & -0.016304 \\
\hline $23 \mathrm{C}$ & -0.281742 & -0.269931 & -0.262299 & -0.011811 & -0.007632 & -0.004179 \\
\hline $24 \mathrm{C}$ & -0.271995 & -0.25433 & -0.245594 & -0.017665 & -0.008736 & -0.008929 \\
\hline $25 \mathrm{C}$ & -0.182313 & -0.13274 & -0.115644 & -0.049573 & -0.017096 & -0.032477 \\
\hline $26 \mathrm{C}$ & -0.301477 & -0.290959 & -0.288016 & -0.010518 & -0.002943 & -0.007575 \\
\hline $27 \mathrm{H}$ & 0.26104 & 0.199071 & 0.194955 & 0.061969 & 0.004116 & 0.057853 \\
\hline $28 \mathrm{H}$ & 0.171978 & 0.137061 & 0.114651 & 0.034917 & 0.02241 & 0.012507 \\
\hline $29 \mathrm{H}$ & 0.152315 & 0.133087 & 0.125846 & 0.019228 & 0.007241 & 0.011987 \\
\hline $30 \mathrm{H}$ & 0.156066 & 0.140432 & 0.128276 & 0.015634 & 0.012156 & 0.003478 \\
\hline $31 \mathrm{H}$ & 0.212435 & 0.154515 & 0.124801 & 0.05792 & 0.029714 & 0.028206 \\
\hline $32 \mathrm{H}$ & 0.175097 & 0.121856 & 0.104057 & 0.053241 & 0.017799 & 0.035442 \\
\hline $33 \mathrm{H}$ & 0.17752 & 0.129562 & 0.105664 & 0.047958 & 0.023898 & 0.02406 \\
\hline
\end{tabular}




\section{Continued}

\begin{tabular}{ccccccc}
\hline $34 \mathrm{H}$ & 0.172398 & 0.132213 & 0.10589 & 0.040185 & 0.026323 & 0.013862 \\
$35 \mathrm{H}$ & 0.175109 & 0.134229 & 0.109376 & 0.04088 & 0.024853 & 0.016027 \\
$36 \mathrm{H}$ & 0.220766 & 0.172545 & 0.186823 & 0.048221 & -0.014278 & 0.062499 \\
$37 \mathrm{H}$ & 0.183776 & 0.14331 & 0.122044 & 0.040466 & 0.021266 & 0.0192 \\
$38 \mathrm{H}$ & 0.16488 & 0.149046 & 0.149029 & 0.015834 & 0.000017 & 0.015817 \\
$39 \mathrm{H}$ & -0.181197 & -0.292784 & -0.314492 & 0.111587 & 0.021708 & 0.089879 \\
$40 \mathrm{H}$ & 0.357286 & 0.324205 & 0.276374 & 0.033081 & 0.047831 & -0.01475 \\
$41 \mathrm{H}$ & 0.375163 & 0.331552 & 0.302288 & 0.043611 & 0.029264 & 0.014347 \\
$42 \mathrm{O}$ & -0.362788 & -0.421728 & -0.470013 & 0.05894 & 0.048285 & 0.010655 \\
\hline
\end{tabular}

Table 4. Mulliken atomic charges, Fukui functions and dual descriptor by B3LYP/6-31G(d) of GP.

\begin{tabular}{|c|c|c|c|c|c|c|}
\hline atom & $q_{k}(N+1)$ & $q_{k}(N)$ & $q_{k}(N-1)$ & $f_{k}^{+}$ & $f_{k}^{-}$ & $\Delta f_{k}(r)$ \\
\hline $1 \mathrm{C}$ & 0.208346 & 0.208888 & 0.204576 & -0.000542 & 0.004312 & -0.004854 \\
\hline $2 \mathrm{C}$ & 0.018775 & 0.000063 & -0.016959 & 0.018712 & 0.017022 & 0.00169 \\
\hline $3 \mathrm{C}$ & 0.299539 & 0.292711 & 0.281844 & 0.006828 & 0.010867 & -0.004039 \\
\hline $4 \mathrm{C}$ & 0.046462 & 0.037318 & 0.029369 & 0.009144 & 0.007949 & 0.001195 \\
\hline $5 \mathrm{H}$ & 0.207505 & 0.193905 & 0.179352 & 0.0136 & 0.014553 & -0.000953 \\
\hline $6 \mathrm{H}$ & 0.179646 & 0.159773 & 0.139164 & 0.019873 & 0.020609 & -0.000736 \\
\hline $7 \mathrm{C}$ & -0.508075 & -0.50687 & -0.505302 & -0.001205 & -0.001568 & 0.000363 \\
\hline $8 \mathrm{H}$ & 0.19998 & 0.186173 & 0.171425 & 0.013807 & 0.014748 & -0.000941 \\
\hline $9 \mathrm{H}$ & 0.203598 & 0.189781 & 0.175425 & 0.013817 & 0.014356 & -0.000539 \\
\hline $10 \mathrm{H}$ & 0.175481 & 0.164012 & 0.151791 & 0.011469 & 0.012221 & -0.000752 \\
\hline $11 \mathrm{~N}$ & -0.439963 & -0.453069 & -0.466947 & 0.013106 & 0.013878 & -0.000772 \\
\hline $12 \mathrm{~N}$ & -0.458297 & -0.452885 & -0.455695 & -0.005412 & 0.00281 & -0.008222 \\
\hline $13 \mathrm{C}$ & 0.566855 & 0.550059 & 0.52607 & 0.016796 & 0.023989 & -0.007193 \\
\hline $14 \mathrm{~N}$ & -0.715656 & -0.716793 & -0.707044 & 0.001137 & -0.009749 & 0.010886 \\
\hline $15 \mathrm{C}$ & -0.290102 & -0.360821 & -0.358308 & 0.070719 & -0.002513 & 0.073232 \\
\hline $16 \mathrm{C}$ & -0.47359 & -0.512709 & -0.525136 & 0.039119 & 0.012427 & 0.026692 \\
\hline $17 \mathrm{C}$ & -0.129222 & -0.133729 & -0.108148 & 0.004507 & -0.025581 & 0.030088 \\
\hline $18 \mathrm{C}$ & -0.183189 & -0.197291 & -0.202209 & 0.014102 & 0.004918 & 0.009184 \\
\hline $19 \mathrm{C}$ & -0.249861 & -0.251301 & -0.256756 & 0.00144 & 0.005455 & -0.004015 \\
\hline $20 \mathrm{C}$ & -0.023031 & -0.024674 & -0.022889 & 0.001643 & -0.001785 & 0.003428 \\
\hline $21 \mathrm{C}$ & -0.142764 & -0.145169 & -0.15742 & 0.002405 & 0.012251 & -0.009846 \\
\hline $22 \mathrm{C}$ & -0.122904 & -0.139501 & -0.136151 & 0.016597 & -0.00335 & 0.019947 \\
\hline $23 \mathrm{H}$ & 0.22121 & 0.195621 & 0.183868 & 0.025589 & 0.011753 & 0.013836 \\
\hline
\end{tabular}




\section{Continued}

\begin{tabular}{|c|c|c|c|c|c|c|}
\hline $24 \mathrm{H}$ & 0.261884 & 0.244926 & 0.231297 & 0.016958 & 0.013629 & 0.003329 \\
\hline $25 \mathrm{H}$ & 0.156373 & 0.126335 & 0.09537 & 0.030038 & 0.030965 & -0.000927 \\
\hline $26 \mathrm{H}$ & 0.110749 & 0.0851 & 0.076219 & 0.025649 & 0.008881 & 0.016768 \\
\hline $27 \mathrm{~S}$ & 0.959989 & 0.876878 & 0.867798 & 0.083111 & 0.00908 & 0.074031 \\
\hline $28 \mathrm{O}$ & -0.42091 & -0.440891 & -0.569464 & 0.019981 & 0.128573 & -0.108592 \\
\hline $29 \mathrm{O}$ & -0.277043 & -0.296304 & -0.407131 & 0.019261 & 0.110827 & -0.091566 \\
\hline $30 \mathrm{~N}$ & -0.740276 & -0.734225 & -0.739524 & -0.006051 & 0.005299 & -0.01135 \\
\hline $31 \mathrm{~N}$ & -0.589541 & -0.591615 & -0.606433 & 0.002074 & 0.014818 & -0.012744 \\
\hline $32 \mathrm{C}$ & -0.385574 & -0.384124 & -0.375045 & -0.00145 & -0.009079 & 0.007629 \\
\hline $33 \mathrm{C}$ & -0.388768 & -0.412243 & -0.378436 & 0.023475 & -0.033807 & 0.057282 \\
\hline $34 \mathrm{C}$ & -0.351337 & -0.339421 & -0.332062 & -0.011916 & -0.007359 & -0.004557 \\
\hline $35 \mathrm{C}$ & -0.080538 & -0.069386 & -0.049977 & -0.011152 & -0.019409 & 0.008257 \\
\hline $36 \mathrm{C}$ & -0.38439 & -0.41688 & -0.427258 & 0.03249 & 0.010378 & 0.022112 \\
\hline $37 \mathrm{C}$ & -0.465385 & -0.413441 & -0.402988 & -0.051944 & -0.010453 & -0.041491 \\
\hline $38 \mathrm{H}$ & 0.226975 & 0.158072 & 0.121962 & 0.068903 & 0.03611 & 0.032793 \\
\hline $39 \mathrm{H}$ & 0.255492 & 0.238187 & 0.178572 & 0.017305 & 0.059615 & -0.04231 \\
\hline $40 \mathrm{H}$ & 0.284047 & 0.268848 & 0.258813 & 0.015199 & 0.010035 & 0.005164 \\
\hline $41 \mathrm{H}$ & 0.224858 & 0.200597 & 0.172862 & 0.024261 & 0.027735 & -0.003474 \\
\hline $42 \mathrm{H}$ & 0.210272 & 0.19969 & 0.154518 & 0.010582 & 0.045172 & -0.03459 \\
\hline $43 \mathrm{H}$ & 0.229828 & 0.177035 & 0.145283 & 0.052793 & 0.031752 & 0.021041 \\
\hline $44 \mathrm{O}$ & -0.473515 & -0.507872 & -0.53313 & 0.034357 & 0.025258 & 0.009099 \\
\hline $45 \mathrm{C}$ & 0.762382 & 0.752213 & 0.720396 & 0.010169 & 0.031817 & -0.021648 \\
\hline $46 \mathrm{O}$ & -0.361116 & -0.366697 & -0.420921 & 0.005581 & 0.054224 & -0.048643 \\
\hline $47 \mathrm{H}$ & 0.302082 & 0.288121 & 0.27532 & 0.013961 & 0.012801 & 0.00116 \\
\hline $48 \mathrm{H}$ & 0.325926 & 0.309066 & 0.302239 & 0.01686 & 0.006827 & 0.010033 \\
\hline $49 \mathrm{H}$ & 0.374759 & 0.352216 & 0.322813 & 0.022543 & 0.029403 & -0.00686 \\
\hline $50 \mathrm{H}$ & 0.315871 & 0.270019 & 0.247632 & 0.045852 & 0.022387 & 0.023465 \\
\hline $51 \mathrm{H}$ & 0.284414 & 0.27008 & 0.219931 & 0.014334 & 0.050149 & -0.035815 \\
\hline $52 \mathrm{H}$ & 0.245043 & 0.207025 & 0.198159 & 0.038018 & 0.008866 & 0.029152 \\
\hline $53 \mathrm{H}$ & 0.262695 & 0.219802 & 0.189433 & 0.042893 & 0.030369 & 0.012524 \\
\hline $54 \mathrm{H}$ & 0.236591 & 0.224992 & 0.166835 & 0.011599 & 0.058157 & -0.046558 \\
\hline $54 \mathrm{H}$ & 0.236591 & 0.154992 & 0.166835 & 0.081599 & -0.011843 & 0.093442 \\
\hline $55 \mathrm{H}$ & 0.248014 & 0.232249 & 0.242516 & 0.015765 & -0.010267 & 0.026032 \\
\hline $56 \mathrm{H}$ & 0.357349 & 0.350258 & 0.316311 & 0.007091 & 0.033947 & -0.026856 \\
\hline $57 \mathrm{H}$ & 0.34124 & 0.326146 & 0.304971 & 0.015094 & 0.021175 & -0.006081 \\
\hline $58 \mathrm{H}$ & 0.400817 & 0.381752 & 0.369194 & 0.019065 & 0.012558 & 0.006507 \\
\hline
\end{tabular}


is controlled by $O(16)$ because it has the highest value of $f_{k}^{-}$and the negative value of $\Delta f_{k}(r)$. In that concerns GP listed in Table 4, the nucleophilic attack centre is $S$ (27) because it has the largest value of $f_{k}^{+}$and the positive value of $\Delta f_{k}(r)$ while $O(28)$ having the largest value of $f_{k}^{-}$and $\Delta f_{k}(r)<0$ is the electrophilic attack centre.

We note that for these three sulfonylureas molecules, the sulfur atom present in each compound is the most probable site for nucleophilic attack and the oxygen atom that shares a double bond with that sulfur atom is the most probable site for electrophilic attack. The different information permits to explain the copper corrosion inhibition mechanism in $\mathrm{HNO}_{3}$ by sulfonylureas.

\section{Copper Corrosion Inhibition Mechanism}

The inhibition of copper corrosion in nitric acid solution by sulfonylureas in particular chlorpropamide, tolazamide and glipizide, is favoured by a protective layer creation on the metal surface. This protective layer is due to the double transfer of electrons between the two entities: molecule $\rightarrow$ copper and copper $\rightarrow$ molecule; justified by $\Delta N$ and $\omega$ values respectively. These electron transfers justify the existence of the chemical adsorption. Moreover, in nitric acid solution some molecules of tolazamide and glipizide can be protonated because they contain heteroatoms:

$$
S f u+H^{+} \rightleftarrows[S f u H]^{+}
$$

Taking into the chlorine atom present in chloropropamide, it will be transformed in cationic form by releasing chloric ion and some of the cationic species could be protonated because they contain also heteroatoms:

$$
\begin{gathered}
S f u C l \rightarrow[S f u]^{+}+C l^{-} \\
{[S f u]^{+}+H^{+} \rightleftarrows[S f u H]^{2+}}
\end{gathered}
$$

There is an interaction between protonated species and $\mathrm{NO}_{3}^{-}$ions adsorbed on the metal surface. In order to explain this phenomenon, a schematic mechanism has been proposed in Figure 4.

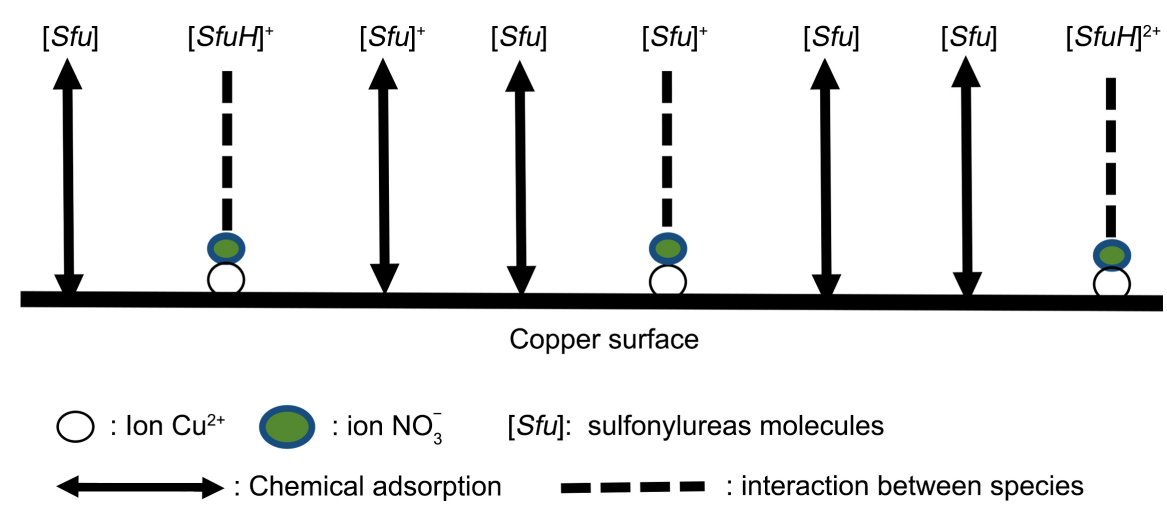

Figure 4. Schematic mechanism of copper corrosion inhibition by sulfonylureas. 


\section{Conclusion}

The analysis of global descriptor parameters $\left(E_{\mathrm{LUMO}}-E_{\mathrm{HOMO}}, \eta, S, \Delta N, \omega, \ldots\right)$ of chloropropamide, tolazamide and glipizide has shown their inhibition properties. It generally appears that these molecules are able to give electrons to the metal, so they can inhibit copper corrosion in nitric acid solution. These descriptor parameters indicate that their inhibition efficiency increases in the following order: glipizide $>$ tolazamide $>$ chloropropamide. The determination of the local parameters $\left(f_{k}^{+}, f_{k}^{-}\right.$and $\Delta f_{k}(r)$ of the studied molecules permitted to specify the centre of electrophilic and nucleophilic attack.

\section{Acknowledgements}

The authors gratefully acknowledged the support of Environmental Training and Research Unit of Daloa (Côte d'Ivoire) and the Laboratory of physical chemistry of Felix Houphouët Boigny university of Abidjan (Côte d'Ivoire).

\section{Conflicts of Interest}

The authors declare no conflicts of interest regarding the publication of this paper.

\section{References}

[1] Nunéz, L., Reguera, E., Corvo, F. and Gonzalez, C. (2005) Corrosion of Copper in Seawater and Its Aerosols in a Tropical Island. Corrosion. Science, 47, 461-484. https://doi.org/10.1016/j.corsci.2004.05.015

[2] Ho, C.E., Chen, W.T. and Kao, C.R. (2001) Interactions between Solder and Metallization during Long-Term Aging of Advanced Microelectronic Packages. Journal of Electronic Materials, 30, 379-385. https://doi.org/10.1007/s11664-001-0047-6

[3] Breslin, C.B. and Macdonald, D.D. (1998) The Influence of UV Light on the Dissolution and Passive Behavior of Copper-Containing Alloys in Chloride Solutions. Portugaliae Electrochimica Acta, 44, 643-651. https://doi.org/10.1016/S0013-4686(98)00109-1

[4] Abiola, O.K. and James, A.O. (2010) The Effects of Aloe Vera Extract on Corrosion and Kinetics of Corrosion Process of Zinc in $\mathrm{HCl}$ Solution. Corrosion Science, 52, 661-664. https://doi.org/10.1016/j.corsci.2009.10.026

[5] Olasunkanmi, L.O., Obot, I.B., Kabanda, M.M. and Ebenso, E.E. (2015) Some Quinoxalin-6-yl Derivatives as Corrosion Inhibitors for Mild Steel in Hydrochloric Acid: Experimental and Theoretical Studies. The Journal of Physical Chemistry $C$, 119, 16004-16019. https://doi.org/10.1021/acs.jpcc.5b03285

[6] Niamien, P.M., Essy, F.K., Trokourey, A., Yapi, A., Aka, H.K. and Diabate, D. (2012) Correlation between the Molecular Structure and the Inhibiting Effect of Some Benzimidazole Derivatives. Materials Chemistry and Physics, 136, 59-65. https://doi.org/10.1016/j.matchemphys.2012.06.025

[7] Obot, I.B. and Obi-Egbedi, N.O. (2010) Adsorption Properties and Inhibition of Mild Steel Corrosion in Sulphuric Acid Solution by Ketoconazole: Experimental and Theoretical Investigation. Corrosion Science, 52, 198-204.

https://doi.org/10.1016/j.corsci.2009.09.002 
[8] El Adnani, Z., Mcharfi, M., Sfaira, M., Benzakour, M., Benjelloun, A.T. and Ebu, M. (2013) DFT Theoretical Study of 7-R-3 Methylquinoxalin-2(1H)-thiones as Corrosion Inhibition in Hydrochloric Acid. Corrosion Science, 68, 223-230. https://doi.org/10.1016/j.corsci.2012.11.020

[9] Popova, A., Christov, M. and Zwetanova, A. (2007) Effect of the Molecular Structure on the Inhibitor Properties of Azoles on Mild Steel Corrosion in $1 \mathrm{M} \mathrm{Hy}$ drochloric Acid. Corrosion Science, 49, 2131-2143. https://doi.org/10.1016/j.corsci.2006.10.021

[10] Palomar-Pardavé, M., et al. (2013) DFT Study of the Adsorption of the Corrosion Inhibitor 2-Mercaptoimidazole onto Fe(100) Surface. Electrochimica Acta, 112, 577-586. https://doi.org/10.1016/j.electacta.2013.08.151

[11] El Adnani, Z., Mcharfi, M., Sfaira, M., Benzakour, M., Benjelloun, A.T. and Ebn Touhami, M. (2013) DFT Theoretical Study of 7-R-3methylquinoxalin-2(1H)-thiones (RH;CH3; Cl) as Corrosion Inhibitors in Hydrochloric Acid. Corrosion Science, 68, 223-230. https://doi.org/10.1016/j.corsci.2012.11.020

[12] Chidiebere, M.A., Oguzie, E.E. and Liu, L. (2015) Adsorption and Corrosion Inhibiting Effect of Riboflavin on Q235 Mild Steel Corrosion in Acidic Environments. Materials Chemistry and Physics, 156, 95-104. https://doi.org/10.1016/j.matchemphys.2015.02.031

[13] Ebenso, E.E., Isabirye, D.A. and Eddy, N.O. (2010) Adsorption and Quantum Chemical Studies on the Inhibition Potentials of Some Thiosemicarbazides for the Corrosion of Mild Steel in Acidic Medium. International Journal of Molecular Sciences, 11, 2473-2498. https://doi.org/10.3390/ijms11062473

[14] Lowmunkhong, P., Ungthararak, D. and Sutthivaiyakit, P. (2010) Triptamine as Corrosion Inhibitor of Mild Steel I Hydrochloric Acid Solution. Corrosion Science, 52, 30-36. https://doi.org/10.1016/j.corsci.2009.08.039

[15] Singh, A.K. and Quraishi, M.A. (2010) Effect of Cefazolin on the Corrosion of Mild Steel in HCl Solution. Corrosion Science, 52, 152-160. https://doi.org/10.1016/j.corsci.2009.08.050

[16] Chauhan, L.R. and Gunasekaran, G. (2007) Corrosion Inhibition of Mild Steel by Plant Extract in Dilute HCl Medium. Corrosion Science, 49, 1143-1161. https://doi.org/10.1016/j.corsci.2006.08.012

[17] Singh, A.K., Mohapatra, S. and Pani, B. (2016) Corrosion Inhibition Effect of Aloe Vera gel: Gravimetric and Electrochemical Study. Journal of Industrial and Engineering Chemistry, 25, 288-297. https://doi.org/10.1016/j.jiec.2015.10.014

[18] Deyab, M.A. (2015), Egyptian Licorice Extract as a Green Corrosion Inhibitor for Copper in Hydrochloric Acid Solution. Journal of Industrial and Engineering Chemistry, 25, 384-389. https://doi.org/10.1016/j.jiec.2014.07.036

[19] Ahmed, R.A. (2016) Investigation of Corrosion Inhibition of Vitamins B1 and C on Mild Steel in $0.5 \mathrm{M} \mathrm{HCl}$ Solution: Experimental and Computational Approach. Oriental Journal of Chemistry, 32, 295-304. https://doi.org/10.13005/ojc/320133

[20] Fucks-Godec, R. and Zergav, G. (2015) Corrosion Resistance of High-Level Hydrophobic Layers Combination with Vitamin E-( $\alpha$-tocopherol) as Green Inhibitor. Corrosion Science, 97, 7-16. https://doi.org/10.1016/j.corsci.2015.03.016

[21] Wazzan, N.A. and Mahgoub, F.M. (2014) DFT Calculations for Corrosion Inhibition of Ferrous Alloys by Pyrazolopyrimidine Derivatives. Open Journal of Physical Chemistry, 4, 6-14. https://doi.org/10.4236/ojpc.2014.41002

[22] Eddy, N.O., Momoh-Yahaya, H. and Oguzie, E.E. (2015) Theoretical and Experi- 
mental Studies on the Corrosion Inhibition Potentials of Some Purines for Aluminium in 0.1 M HCl. Journal of Advanced Research, 6, 203-217. https://doi.org/10.1016/j.jare.2014.01.004

[23] Ju, H., Kai, Z.P. and Li, Y. (2008) Aminic Nitrogen-Bearing Polydentate Schiff Base Compounds as Corrosion Inhibitors for Iron in Acidic Media: A Quantum Chemical Calculations. Corrosion Science, 50, 865-871. https://doi.org/10.1016/j.corsci.2007.10.009

[24] Chan, G.K.-L. (1999) A Fresh Look at Ensembles: Derivative Discontinuities in Density Functional Theory. The Journal of Chemical Physics, 110, 4710-4723. https://doi.org/10.1063/1.478357

[25] Obot, I.B. and Obi-Egbedi, N.O. (2008) Inhibitory Effect and Adsorption Characteristics of 2, 3-Diaminonaphthalene at Aluminum/Hydrochloric Acid Interface: Experimental and Theoretical Study. Surface Review and Letters, 15, 903-910. https://doi.org/10.1142/S0218625X08012074

[26] Sen, K.D. (1987) Eletronegativity, Structure and Bonding 66. Springer-Verlag, Berlin, 27. https://doi.org/10.1007/BFb0029833

[27] Sen, K.D. (1993) Chemical Hardness, Structure and Bonding 80. Springer-Verlag, Berlin, 79. https://doi.org/10.1007/BFb0036795

[28] Parr, R.G. and Yang, W. (1989) Density Functional Theory of Atoms and Molecules. Oxford University Press, Oxford, 26-33.

[29] Chattaraj, P.K., Sarkar, U. and Roy, D.R. (2006) Electrophilicity Index. Chemical Reviews, 106, 2065-2091. https://doi.org/10.1021/cr040109f

[30] Parr, R.G. and Yang, W. (1984) Density Functional Approach to the Frontier Electron Theory of Chemical Reactivity. Journal of the American Chemical Society, 106, 4049-4050. https://doi.org/10.1021/ja00326a036

[31] Morell, C., Grand, A. and Toro-Labbé, A. (2005) New Dual Descriptor for Chemical Reactivity. Journal of Physical Chemistry A, 109, 205-212. https://doi.org/10.1021/jp046577a

[32] Frisch, M.J., Trucks, G.W., Schlegel, H.B., Scuseria, G.E., Robb, M.A., Cheeseman, J.R., Scalmani, G., Barone, V., Mennucci, B., Petersson, G.A., Nakatsuji, H., Caricato, M., Li, X., Hratchian, H.P., Izmaylov, A.F., Bloino, J., Zheng, G., Sonnenberg, J.L., Hada, M., Ehara, M., Toyota, K., Fukuda, R., Hasegawa, J., Ishida, M., Nakajima, T., Honda, Y., Kitao, O., Nakai, H., Vreven, T., Montgomery, J.A., Peralta, J.E., Ogliaro, F., Bearpark, M., Heyd, J.J., Brothers, E., Kudin, K.N., Staroverov, V.N., Kobayashi, R., Normand, J., Raghavachari, K., Rendell, A., Burant, J.C., Iyengar, S.S., Tomasi, J., Cossi, M., Rega, N., Millam, J.M., Klene, M., Knox, J.E., Cross, J.B., Bakken, V., Adamo, C., Jaramillo, J., Gomperts, R., Stratmann, R.E., Yazyev, O., Austin, A.J., Cammi, R., Pomelli, C., Ochterski, J.W., Martin, R.L., Morokuma, K., Zakrzewski, V.G., Voth, G.A., Salvador, P., Dannenberg, J.J., Dapprich, S., Daniels, A.D., Farkas, Ö., Foresman, J.B., Ortiz, J.V., Cioslowski, J. and Fox, A.D.J. (2009) Gaussian 09. Gaussian, Inc., Wallingford, CT.

[33] Lee, C., Yang, W. and Parr, R.G. (1988) Development of the Colle-Salvetti Correlation-Energy Formula into a Functional of the Electron Density. Physical Review B, 37, 785-789. https://doi.org/10.1103/PhysRevB.37.785

[34] Becke, A.D. (1993) Density-Functional Thermochemistry. III. The Role of Exact Exchange. Journal of Chemical Physics, 98, 1372-1377. https://doi.org/10.1063/1.464913

[35] Mulliken, R.S. (1955) Electronic Population Analysis on LCAOMO Molecular Wave Functions. Journal of Chemical Physics, 23, 1833-1840. 
https://doi.org/10.1063/1.1740588

[36] Koopmans, T. (1934) About the Assignment of Wave Functions and Eigenvalues to the Individual Electrons of Atoms. Über die Zuordnung von Wellenfunktionen und Eigenwerten zu den Einzelnen Elektronen Eines Atoms. Physica, 1, 104-113. https://doi.org/10.1016/S0031-8914(34)90011-2

[37] Parr, R.G. and Yang, W. (1983) Absolute Hardness: Comparrion Parameter to Absolute Electronegativity. Journal of the American Chemical Society, 105, 7512-7516. https://doi.org/10.1021/ja00364a005

[38] Yang, W. and Parr, R.G. (1986) Absolute Electronegativity and Hardness Correlated with Molecular Orbital Theory. Proceeding of the National Academy of Sciences, 83, 8440-8441. https://doi.org/10.1073/pnas.83.22.8440

[39] Pearson, R.G. (1963) Hard and Soft Acids and Bases. Journal of the American Chemical Society, 85, 3533-3539. https://doi.org/10.1021/ja00905a001

[40] Huheey, J.E. (1965) The Electronegativity of Groups. Journal of Chemical Physics, 69, 3284-3291. https://doi.org/10.1021/j100894a011

[41] Vela, A. and Gazquez, J.L. (1990) A Relationship between the Static Dipole Polarizability, the Global Softness, and the Fukui Function. Journal of the American Chemical Society, 112, 1490-1492. https://doi.org/10.1021/ja00160a029

[42] Parr, R.G., Szentpaly, L. and Liu, S. (1999) Electrophilicity Index. Journal of the American Chemical Society, 121, 1922-1924. https://doi.org/10.1021/ja983494x

[43] Pearson, R.G. (1988) Absolute Electronegativity and Hardness: Application to Inorganic Chemistry. Inorganic Chemistry, 27, 734-740. https://doi.org/10.1021/ic00277a030

[44] Michaelson, H.B. (1977) The Work Function of the Elements and Its Periodicity. Journal of Applied Physics, 48, 4729-4733. https://doi.org/10.1063/1.323539

[45] Dewar, M.J.S., Zoebisch, E.G., Healy, E.F. and Stewart, J.P. (1985) Development and Use of Quantum Mechanical Molecular Models, 76, AM1: A New General Purpose Quantum Mechanical Molecular Model. Journal of the American Chemical Society, 107, 3902-3909. https://doi.org/10.1021/ja00299a024

[46] Mendez, F. and Gazquez, J.L. (1994) Reactivity of Enolate Ions: The Local Hard and Soft Acids and Bases Principle Viewpoint. Journal of the American Chemical Society, 116, 9298-9301. https://doi.org/10.1021/ja00099a055

[47] Yang, W. and Mortier, W.J. (1986) The Use of Global and Local Molecular Parameters for the Analysis of the Gas-Phase Basicity of Amines. Journal of the American Chemical Society, 108, 5708-5711. https://doi.org/10.1021/ja00279a008

[48] Dewar, M.J.S. and Thiel, W. (1977) Ground States of Molecules, the MNDO Method Approximations and Parameters. Journal of Chemical Physics, 99, 4899-4907. https://doi.org/10.1021/ja00457a004

[49] Obi-Egbedi, N.O., Obot, I.B. and El-Khaiary, M.I. (2011) Quantum Chemical Investigation and Statistical Analysis of the Relationship between Corrosion Inhibition Efficiency and Molecular Structure of Xanthene and Its Derivatives on Mild Steel in Sulphuric Acid. Journal of Molecular Structure, 1002, 86-96. https://doi.org/10.1016/j.molstruc.2011.07.003

[50] Awad, M.K., Mustafa, M.R. and Abo Elnga, M.M. (2010) Computational Simulation of the Molecular Structure of Some Triazoles as Inhibitors for the Corrosion of Metal Surface. Journal of Molecular Structure (Theochem), 959, 66-74. https://doi.org/10.1016/j.theochem.2010.08.008

[51] Bereket, G., Hür, E. and Ogretir, C. (2002) Quantum Chemical Studies on Someimi- 
dazole Derivatives as Corrosion Inhibitors for Iron in Acidic Medium. Journal of Molecular Structure Theochem, 578, 79-88.

https://doi.org/10.1016/S0166-1280(01)00684-4

[52] Zhang, S.G., Lei, W., Xia, M.Z. and Wang, F.Y. (2005) QSAR Study on N-Containing Corrosion Inhibitors: Quantum Chemical Approach Assisted by Topological Index. Journal of Molecular Structure: THEOCHEM, 732, 173-182.

https://doi.org/10.1016/j.theochem.2005.02.091

[53] Quraishi, M. and Sardar, R. (2003) Hector Bases-A New Class of Heterocyclic Corrosion Inhibitors for Mild Steel in Acid Solutions. Journal of Applied Electrochemistry, 33, 1163-1168. https://doi.org/10.1023/B:JACH.0000003865.08986.fb

[54] Khalil, N. (2003) Quantum Chemical Approach of Corrosion Inhibition. Portugaliae Electrochimica Acta, 48, 2635-2640.

https://doi.org/10.1016/S0013-4686(03)00307-4

[55] Khaled, K.F. (2008) Molecular Simulation, Quantum Chemical Calculations and Electrochemical Studies for Inhibition of Mild Steel by Triazoles. Electrochimica Acta, 53, 3484-3492. https://doi.org/10.1016/j.electacta.2007.12.030

[56] Saha, S.K., et al. (2015) Density Functional Theory and Molecular Dynamics Simulation Study on Corrosion Inhibition Performance of Mild Steel by Mercapto-Quinoline Schiff Base Corrosion Inhibitor. Physica E: Low-Dimensional Systems and Nanostructures, 66, 332-341. https://doi.org/10.1016/j.physe.2014.10.035

[57] Chakraborty, T., Gazi, K. and Ghosh, D.C. (2010) Computation of the Atomic Radii through the Conjoint Action of the Effective Nuclear Charge and the Ionization Energy. Molecular Physics, 108, 2081-2092.

https://doi.org/10.1080/00268976.2010.505208

[58] Obot, I.B. and Gasem, Z.M. (2014) Theoretical Evaluation of Corrosion Inhibition Performance of Some Pyrazine Derivatives. Corrosion Science, 83, 359-366. https://doi.org/10.1016/j.corsci.2014.03.008

[59] Lukovits, I., Kalman, E. and Zucchi, F. (2001) Corrosion Inhibitors-Correlation between Electronic Structure and Efficiency. Corrosion, 57, 3-8. https://doi.org/10.5006/1.3290328

[60] Hohenberg, P. and Kohn, W. (1964) Inhogeneous Electron Gas. Physical Review, 136, B864-B871. https://doi.org/10.1103/PhysRev.136.B864

[61] Nwankwo, H.U., Olasunkanmi, L.O. and Ebenso, E.E. (2017) Experimental, Quantum Chemical and Molecular Dynamic Simulations Studies on the Corrosion Inhibition of Mild Steel by Some Carbazole Derivatives. Scientific Report, 7, 2436-2446. https://doi.org/10.1038/s41598-017-02446-0

[62] Martínez-Araya, J.I. (2015) Why Is the Dual Descriptor a More Accurate Local Reactivity Descriptor than Fukui Functions? Journal of Mathematical Chemistry, 53, 451-465. https://doi.org/10.1007/s10910-014-0437-7 